\title{
LUCAS CRANACH, EL VIEJO Y FRANS FLORÍS: PINTURAS FIRMADAS, EN COLECCIONES ESPAÑOLAS
}

\author{
POR \\ ELISA BERMEJO \\ Departamento de Historia de Arte «Diego Velázquez»
}

\begin{abstract}
Two unpublished paintings in the Spanish Collections, the Portrait of a Lady by Lucas Cranach the Elder, and the Four Evangelist by Frans Floris are considered.
\end{abstract}

Es fácilmente comprobable el escaso número de pinturas alemanas, del siglo XVI, llegadas a España. Varias pueden ser las razones que lo motivaron pero, seguramente, las que influyeron de manera más decisiva hay que situarlas dentro de las características de la sociedad española de la época. En aquellos momentos de nuestra historia los principales clientes del país, interesados en adquirir pinturas de escuelas extranjeras, pertenecían, en su mayoría a instituciones religiosas o eran personajes de la corte, la nobleza y la alta burguesía que deseaban favorecer Iglesias o Capillas, a través de fundaciones, en relación con sus familias o su especial devoción.

Desde el siglo XV, además, se seguía la tradición de la Corte cuyos gustos se inclinaban, decididamente, por las tablas al óleo de reconocida calidad, procedentes de los Países Bajos. $\mathrm{Si}$ a esto se añade que en Alemania se inicia, en aquellos momentos, la gran transformación que supuso la Reforma liderada por Lutero, gran amigo de Lucas Cranach, resulta, en cierto modo, explicable que la clientela española no estuviese interesada en hacer encargos de pintura de procedencia protestante.

Sirva de ejemplo la pintura alemana que conserva el Museo del Prado, de Madrid. De Alberto Durero (+1528) la pareja de espléndidas tablas con Adán y Eva y su Autorretrato. De Hans Baldung Grien (+1545), La Armonía o Las tres Gracias y su pareja Las Edades y la Muerte y de Lucas Cranach, El Viejo (+1553) dos pinturas con episodios de la Cacería en honor de Carlos $V$ en el Castillo de Torgau ya de fecha tardía (1544 y 1545). En años muy recientes ha ingresado en el Prado una Virgen con el Niño, San Juan y ángeles con fecha en 1556 lo que evidencia que será obra, probable de Lucas, el segundo hijo del llamado Cranach, el Viejo ${ }^{1}$.

Pintura con gran calidad, de Lucas Cranach, es una tabla con el Calvario firmada y fechada que, procedente de Badajoz, se adquirió de la Escuela de Cristo, de Sevilla, para el Museo de Bellas Artes de esta ciudad. La publicó, en 1972, Angúlo Íñiguez y dice de ella:

• J. J. Luna: Catálogo, Museo del Prado: Últimas adquisiciones. 1982-1995. Madrid, 1995, nº 40, p. 96. 
«ninguna, incluidas las del Museo del Prado, le igualan en calidad pictórica» ${ }^{2}$. Todo lo demás que se conoce son copias o imitaciones de escasa calidad.

No hay que olvidar, sin embargo, la gran difusión que tuvieron, entre nuestros artistas, las estampas o grabados alemanes que llegaron desde fecha temprana y fueron aprovechados en numerosas composiciones sobre todo, los de Durero.

\section{LUCAS CRANACH, EL VIEJO (Kronach 1472-Weimar 1553):}

Retrato de la Duquesa Inés, mujer de Otón el Magno. Óleo sobre tabla $(14,5$ x 14,5 cm).

Firma con dragoncillo o serpiente con las alas levantadas y fecha de 1529.

$\mathrm{Al}$ reverso de la tabla figura una inscripción latina en caracteres dorados sobre fondo negro, con intención de identificar a la retratada (Figs. 1 y 3 ).

Antes de iniciar el estudio, de esta pintura que ahora se da a conocer, parece de interés repasar la trayectoria personal y artística de su autor en años y circunstancias coetáneos a la realización de esta deliciosa tablita que se corresponden con la larga estancia de Lucas Cranach en Wittenberg. También conviene recordar que el artista había nacido, 1472, en Kronach ciudad en la frontera fracosajona perteneciente a la Alta Franconia de la que toma su apellido y que murió y fue enterrado en Weimar, en 1553, en la iglesia de Santiago del cementerio.

Consta que, desde comienzos del siglo XVI, el prestigio artístico de Lucas Cranach estaba consolidado como lo demuestra el que, en 1504, el Elector de Sajonia Federico el Sabio, solicitara sus servicios como pintor de Corte cargo que Cranach aceptó el siguiente año tras una breve etapa de estancia en Viena (1501-1504). En Enero de 1508, como pintor de Corte, fue honrado por Federico con blasón o escudo de armas en el que figuraba la serpiente o dragoncillo con alas de murciélago levantadas con el que, a partir de esa fecha comenzó a firmar la mayoría de sus obras. Antes, 1504-1506, lo hacía con su monograma compuesto por las iniciales LC entrelazadas.

Poco después emplearía, únicamente, el símbolo que le había sido concedido como blasón, para firmar sus pinturas entre 1515 y 1537 fecha, ésta última, del fallecimiento en Bolonia, de su hijo mayor Hans y, precisamente, a partir de ese año las alas de murciélago se transforman, con tendencia a alas de pájaro y ya no enhiestas sino abatidas.

La estancia en Wittenberg supuso para Cranach una continua sucesión de éxitos tanto en su carrera personal como para el reconocimiento de su arte de pintor. El registro de impuestos, de Wittenberg de 1510, recoge por vez primera el nombre de Cranach, probablemente, tras una breve estancia en los Países Bajos (1508-1509). Consta, también, que adquirió varias casas en Wittenberg y, en 1519, obtuvo el nombramiento de tesorero del Concejo Municipal de la ciudad, junto a otros privilegios concedidos por el Elector Federico el Sabio. Al morir este, en 1525, le sucede en el cargo su hermano Juan el Constante que también protegió al artista durante los siete años que vivió y ejerció como Elector, nombrándole Consejero en $1525 / 26,1528 / 29$ y 1531/32. Por otra parte, los datos sobre distribución de la renta de la ciudad, en el año de 1528 ponen de manifiesto que Cranach se contaba entre los más ricos habitantes de la misma.

Durante el mandato de Juan el Constante parece que, el pintor, no tuvo que realizar trabajos importantes para la Corte a pesar de conservar el cargo de pintor oficial lo que le permitió aceptar encargos de otros patronos para continuar después con su buena estrella al lle-

2 D. Angulo Íñiguez: «Lucas Cranach: El Calvario de 1538 del Museo de Sevilla». Archivo Español de Arte. Madrid, 1972, nº 177, pp. 1-7; IV láms. 

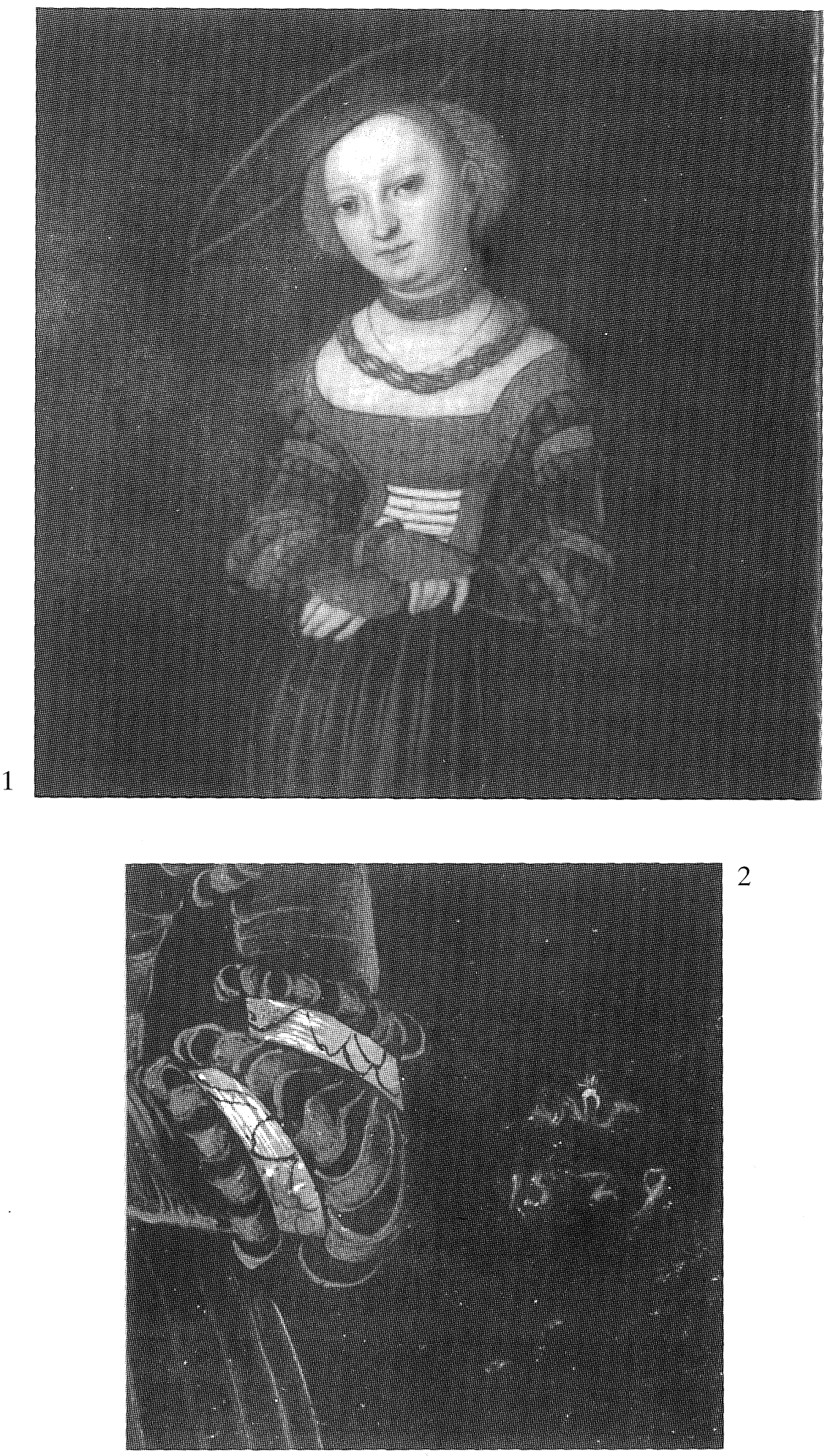

Figura 1 y 2. Lucas Cranach, El Viejo, Retrato de la Duquesa Inés y detalle de la firma del pintor. 
gar como sucesor el tercer Elector, Juan Federico el Magnánimo, con el que volvió a ser Consejero en 1534/35 y llegó a ser elegido burgomaestre o alcalde, de Wittemberg, en 1537, cargo que disfrutó hasta 1544.

Es importante señalar que, además de los tres Electores citados, entre los patronos que hicieron encargos a Lucas Cranach figuran los nombres de los más famosos personajes de la historia de su tiempo: el Emperador Maximiliano I, Carlos V, y aún figuras de la llamada «Vieja Iglesia» como el poderoso Cardenal Alberto de Brandenburgo el más destacado protagonista de la Alemania de esta época. Parece que Cranach comenzó a recibir encargos del Cardenal en 1520 y continuó trabajando para él hasta 1527, es decir, en la etapa más brillante de este Príncipe de la Iglesia. Sorprenden, un tanto, estas dispares actividades de Cranach pero conviene recordar que en los primeros momentos de la Reforma protestante ni el propio Lutero ni Federico el Sabio tenían clara conciencia de una ruptura radical con la Iglesia Católica y, por otra parte, cuando Cranach se posicionó del lado del reformador, el pintor se sentía con la suficiente autoridad como para escoger con libertad su elección sin que ello supusiera, en absoluto, una dedicación exclusiva hacia alguno de los dos bandos, adversos. Puede decirse que Cranach pintó, entonces, abundantes retratos tanto del Cardenal como de Lutero, los dos enconados oponentes.

Para el propósito de este estudio lo más interesante de la carrera artística, del pintor alemán, son los años que estuvo al servicio de Juan el Constante en los que éste desempeño el cargo de Elector en Wittemberg, es decir de 1525 a 1532, años en los que el arte de Lucas Cranach está, como es lógico, en relación muy directa con el estilo que refleja el retrato, que ahora se publica, realizado en 1529 y por ello conviene recoger lo más característico de su personalidad artística en esa etapa.

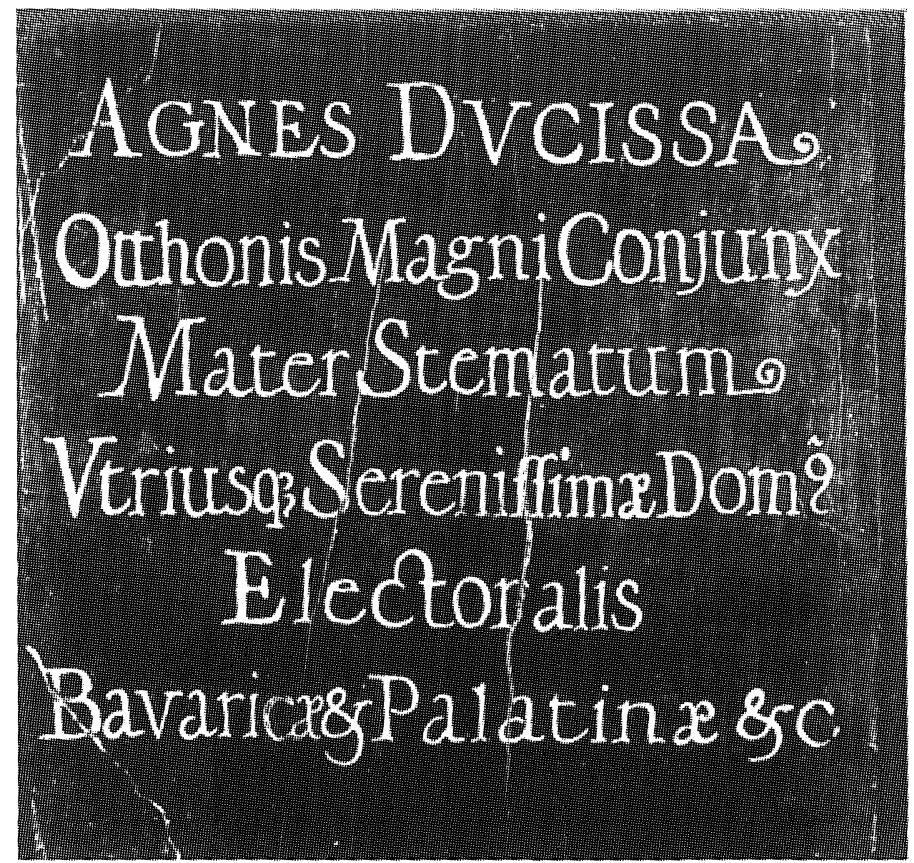

Figura 3. Lucas Cranach, El Viejo, Reverso de retrato de la Duquesa Inés. Colección particular española ${ }^{3}$.

${ }^{3}$ La traducción de la inscripción es: Inés Duquesa, mujer de Oton el Grande, madre de las ramas genealógicas de las serenísimas casas electorales de Baviera, el Palatinado y otras. 

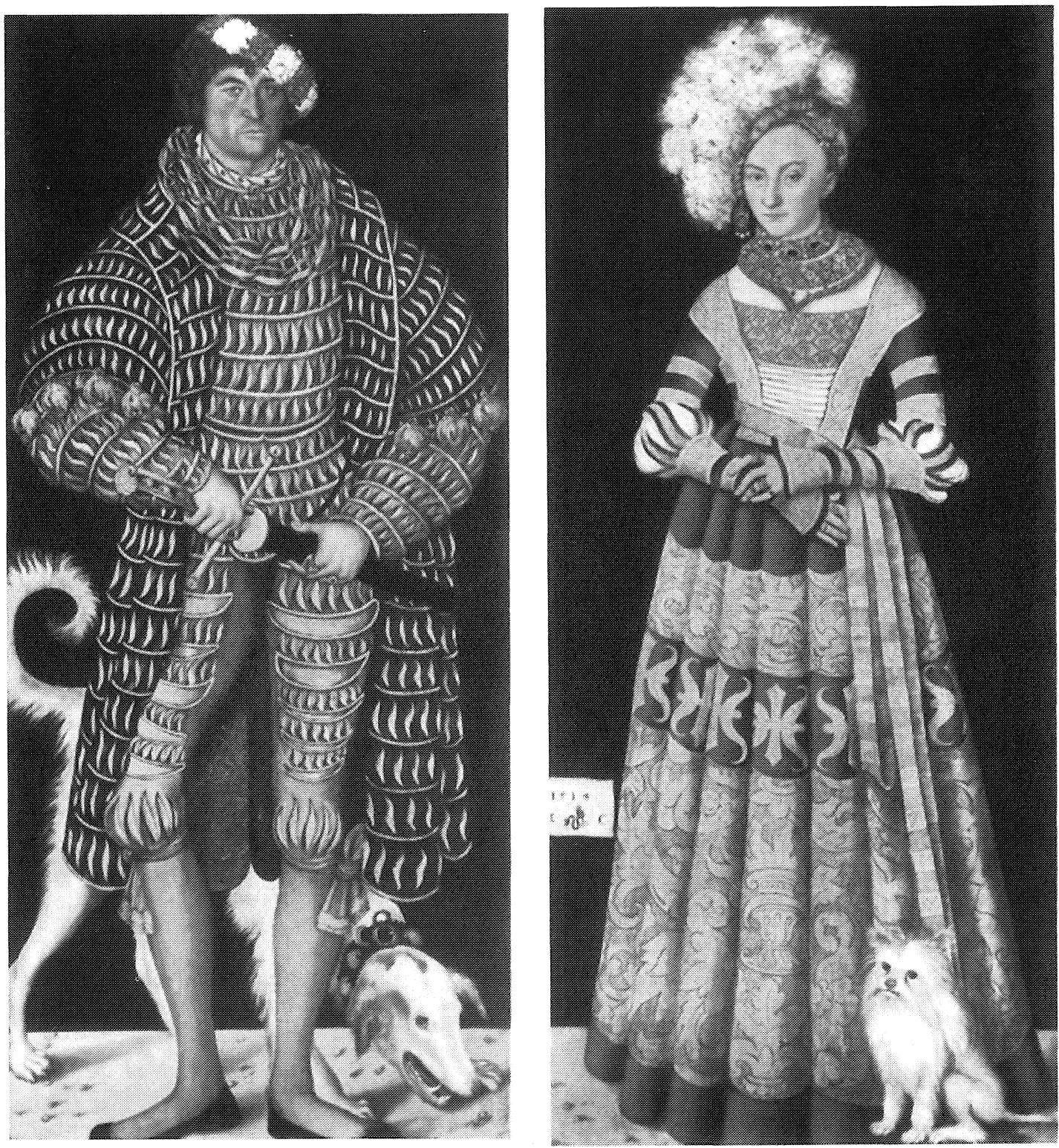

Figuras 4 y 5. Lucas Cranach, El Viejo: Retratos de Enrique el Piadoso y de su mujer. Dresde. Museo. 
Se ha dicho que entre los más reconocidos pintores alemanes, nacidos hacia la década de los años setenta, del siglo XV, Lucas Cranach pareció situarse fuera de su tiempo y aún por los temas que trató y por su actitud moderna se le llegó a considerar como un gótico tardío y caprichoso. Sin embargo, lo que consigue es un estilo muy personal que no persigue una determinada tendencia sino que cultiva una especial originalidad. Dentro del panorama del Renacimiento alemán está a la altura de Matías Grünewald, Burgkmair y aún de otros más jóvenes tales como Hans Baldung Grien, Albrecht Altdorfer o Hans Holbein.

Al analizar el estilo de Cranach el Viejo, como pintor de retratos, que es lo que aquí se pretende, se advierte que los realizados desde su llegada a Wittemberg muestran una notable transformación al desaparecer, en ellos, los complicados fondos con tendencia al misterio y sustituirlos por otros unidos y neutros que confieren a los retratados el aspecto de estar pendientes, ante todo, de ellos mismos. Como, en general, suelen basarse en modelos que el artista dibuja o pinta del natural, dan la impresión de estar captados en un momento preciso y su iluminación trata de conseguir un modelado con tendencia a luz uniforme y coloración local que les añade encanto y cierto carácter ornamental.

Los modelos de Cranach no siempre alcanzan un aspecto atractivo pero logran comunicar un especial tono de serena distinción y sentido aristocrático que los hace fascinantes. En definitiva, conseguían satisfacer, plenamente, los gustos de la nobleza y de la alta burguesía alemana que se convirtió en una clientela fiel identificada con la manera de hacer del pintor.

Los numerosos retratos de Lucas Cranach, que han llegado a nosotros, constituyen una parte importante de su obra y vamos a dedicar una especial atención a los que representan damas y jovencitas elegantes, de aspecto refinado, con un punto de concesión a la coquetería femenina que, el artista, realza sirviéndose de una técnica muy personal.

Dos puntos llaman nuestra atención en la presentación de los modelos femeninos, bien sean de cuerpo entero o poco más de media figura como el de la tablita que publicamos. En primer lugar la repetición de su actitud y gesto: plantadas ante un fondo unido, con la cabeza ligeramente inclinada y las manos cruzadas, a la altura de la cintura, apoyando una sobre la otra. El otro punto de atención es probable que sea consecuencia de una lenta y tradicional evolución germánica en la indumentaria femenina pero, también, es posible que responda a un particular gusto del pintor que, a juzgar por su éxito a través de los años, debía de coincidir con el de las mujeres jóvenes y menos jóvenes que se hicieron retratar por Cranach.

Especialmente característicos del pintor son los trajes de amplias y largas faldas resueltas con unos pliegues a los que se podría denominar «tubulares» que bajan desde la cintura abriéndose hacia el borde. La parte superior, ajustada a la figura, consta de un corpiño cerrado, sobre la camisa blanca, por unos cordones negros y rematada por un amplio escote que, en varios ejemplares, aparece velado por la sutil transparencia de la tela de la camisa. Las mangas, muy elaboradas, con bullones de rollo y aplicaciones de bordados en tonos dorados presentan, también, otro especial punto de atención y es que, invariablemente, llevan un puño que se alarga por arriba y cubre media mano.

El color y calidades de las telas son otra nota, creemos que muy personal de Cranach. En la mayoría de los casos son de un rojo, que diríamos, guinda con pinceladas luminosas que le dan textura de terciopelo aunque utiliza, en algunos otros, un verde intenso de similar elegancia.

Otra constante es el empleo de adornos, de joyas en oro, que engalanan los cuellos de sus modelos con ajustadas gargantillas decoradas con piedras preciosas y pesadas cadenas de eslabones a la moda de Sajonia. Este deseo de vistosa elegancia alcanza también a los peinados y muchas de las damas llevan el cabello recogido por una redecilla de perlas. 
La tablita con el retrato de la Duquesa Inés, responde a todos los detalles de indumentaria que hemos señalado pero se adorna, además, con un sombrero plano, con amplia ala en el mismo tipo de tejido y color que el resto del traje, es decir, en rojo-guinda aterciopelado, que también, lucen otros ejemplares. Este tipo de color en la indumentaria permite, por contraste, destacar la fina blancura del rostro de matices eslavos: cara redonda, y pómulos salientes, con ojos claros oblicuos y rasgados (Fig. 1). Este tipo de rostros, como se verá, se hace particularmente fascinante, por su aire felino y suavidad, en los delicados desnudos que Cranach pinta para complacer a una buena parte de sus clientes, componiendo escenas propias de la época que recrean la «antigüedad pagana» como Venus, Apolo y Diana o sus numerosas versiones del «Juicio de Paris». Como ejemplos que apoyan cierto espíritu conservador que caracteriza a los retratos femeninos de Cranach o quizás producto del gusto original de la propia personalidad del pintor traemos a estas páginas retratos y escenas en los que se aprecia una estrecha relación con la Duquesa Inés de colección española, tanto por su presentación y actitudes como por la semejanza en la indumentaria.

Para comenzar reproducimos el retrato de la Mujer de Enrique el Piadoso (184,5 x 82,5 $\mathrm{cm}$. Dresde Museo) que forma pareja con el de su marido pero es el de la dama el que va firmado y fechado, en una fecha bastante temprana, sobre una a modo de tarjeta blanca que resalta al borde izquierdo, del fondo neutro oscuro, con la fecha 1514, arriba y debajo el símbolo de la serpiente con las alas levantadas entre las iniciales LC. (Figs. 4 y 5$)^{4}$.

David y Betsabé (36 x $24 \mathrm{~cm}$. Berlín Museo) se convierte para Cranach en una tierna escena compuesta por cinco jovencitas en diversas actitudes llenas de naturalidad de las que hemos escogido el detalle de las dos del lateral derecho porque sus trajes de forma y color así como el sombrero tienen gran semejanza con la dama de nuestra pintura. Va firmada con serpiente de alas levantas entre la fecha 15-26. (Fig. 7).

Es curioso ver como, los desnudos de una de sus versiones del Juicio de París (35 x 24 $\mathrm{cm}$. Karlsruhe, Kunsthalle), firmado con serpiente de alas levantadas y fechado en 1530, los realiza con un dibujo armonioso, de línea muy fina que modela sus cuerpos pero no renuncia a la coquetería y a los detalles de femenina elegancia como pueden ser las cadenas de oro, la redecilla de perlas que recoge el cabello de una de ellas o el sombrero que luce la otra. Escogemos, precisamente, el detalle de estas graciosas y seductoras figurillas (Fig. 9).

Entre las numerosas representaciones de Judit debidas a Cranach, que también repite su taller, existe una firmada con la serpiente de alas levantadas según Ruhmer y abatidas según Rosemberg, pero sin fechar (180 x 56 cm. San Francisco de California. Palacio de la Legión de Honor) que va vestida como la del ejemplar que damos a conocer y que según el catalogo del Museo (1960) representa a «Una dama de la Corte de Sajonia como Judit». La incluimos porque según opinión de Rosemberg debería fecharse $c a$ 1537-1540 y es posible que así sea ya que en la reproducción, que conocemos, parece que la firma o sea el dragoncillo tiene caídas las alas. Traje, corpiño, cadenas y hasta el detalle del puño de la manga que cubre parte de la mano sigue sin modificar los modelos con fecha mucho más temprana (Fig. 6).

Por estar firmada y fechada en 1529, es decir, el mismo año que el retrato de colección española citamos la Cacería de ciervos del Elector Federico el Sabio (80 x 114; Viena. Kunsthistorisches Museum) en la que aparecen al centro del primer término, el emperador Maximiliano, junto a Federico el Sabio y el Elector Juan el Constante, hacia la derecha, como cazadores. Seguramente fue éste quien lo encargó puesto que Federico el Sabio había

${ }^{4}$ E. Ruhmer: Cranach. Phaidon. Edit. Noguer. Barcelona 1963. Max J. Fiédländer y Jacobo Rosenberg. Sotheby Parke Bernet (Publicada como Die Gemälde von Lucas Cranach. Berlín, 1932). Reimpresión revisada 1978. 


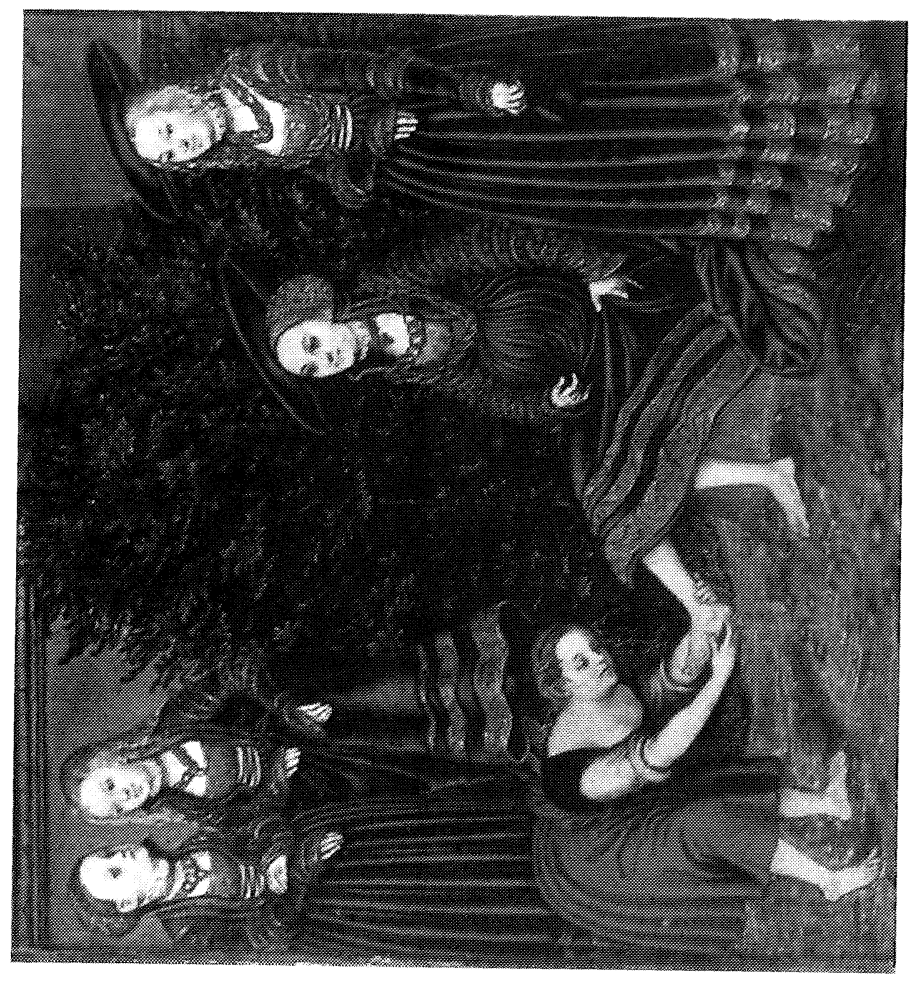

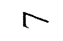

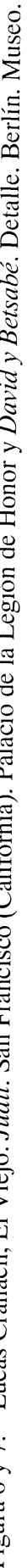




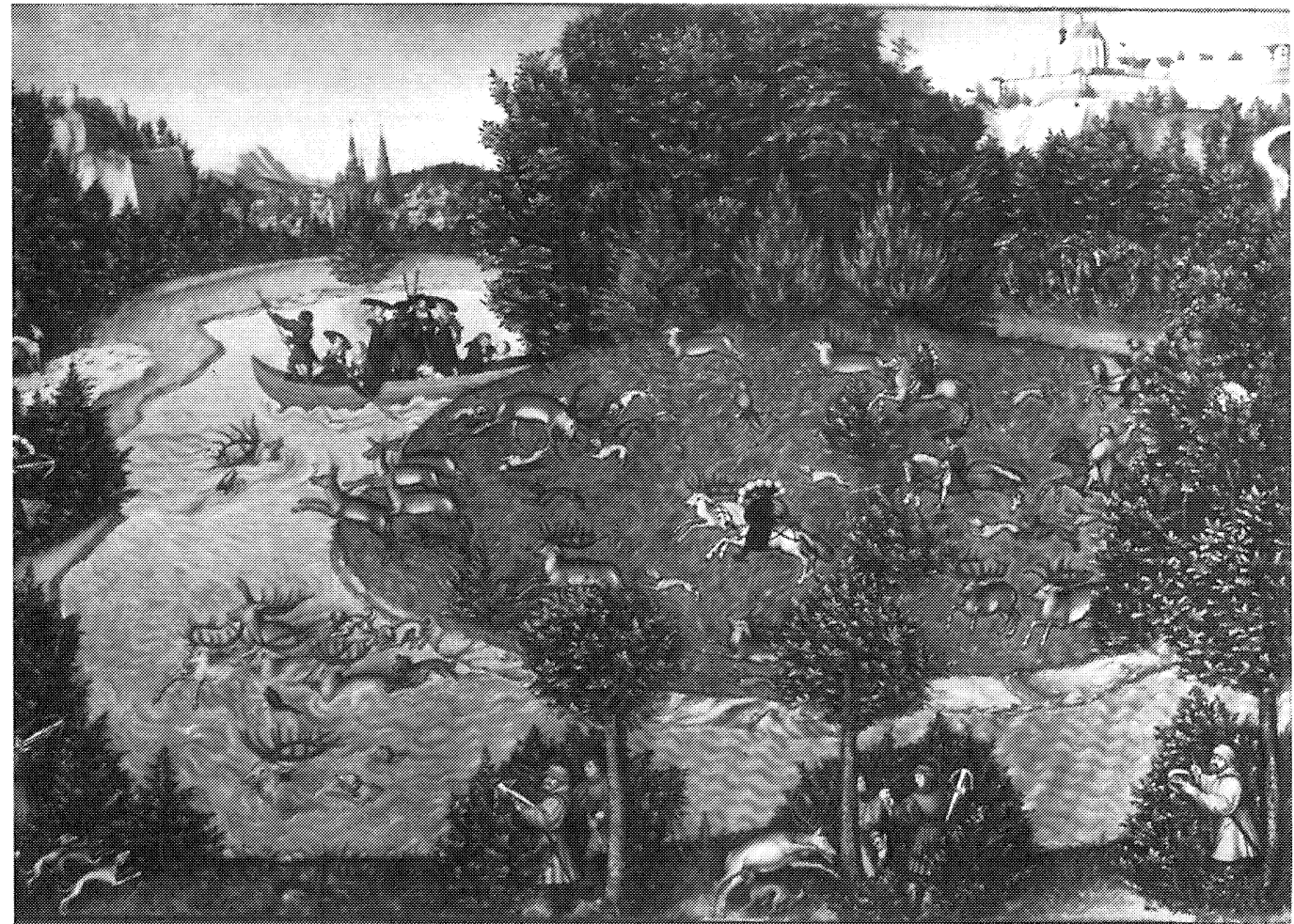

8

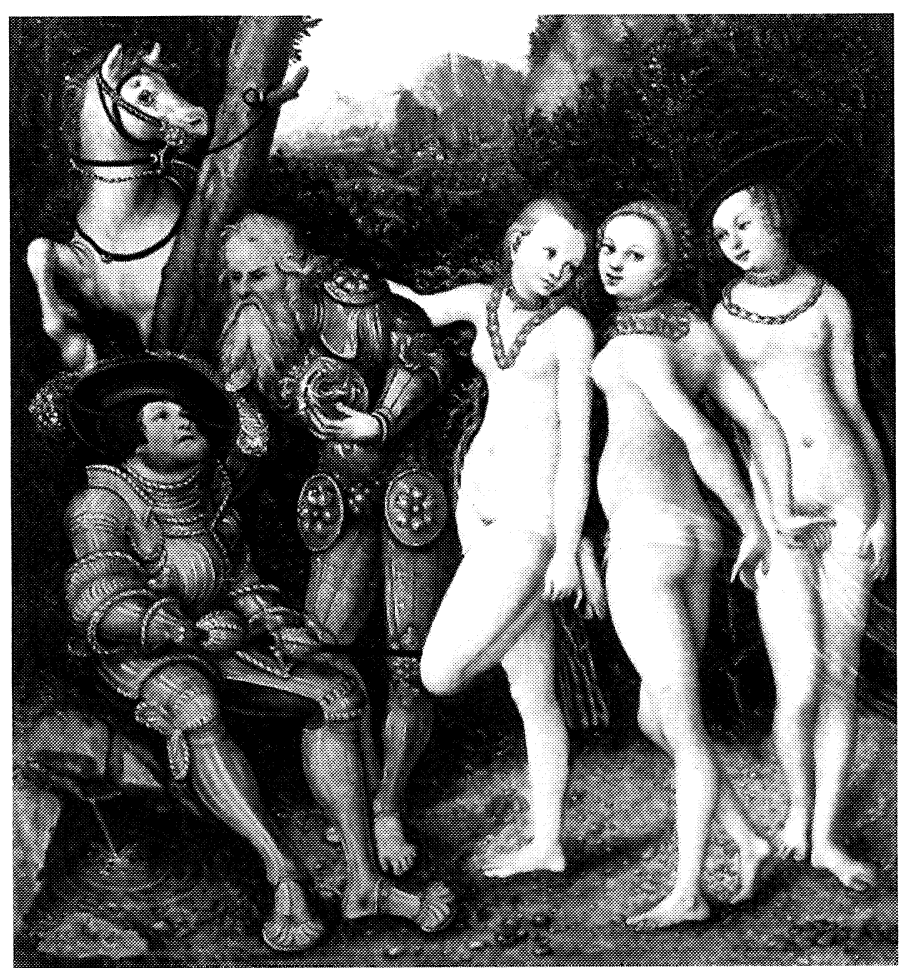

Figura 8 y 9. Lucas Cranach, El Viejo: Cacería de ciervos de Federico el Sabio. Viena. Kunsthistorisches. Museum y Detalle. El Juicio de París. Karlsruhe, Kunsthalle. 
muerto en 1525 y Maximiliano en 1519. Al fondo del cuadro, a punto de navegar por el río aparece una embarcación con un grupo de caballeros y damas vestidas éstas con igual indumentaria que las de los ejemplos que acabamos de citar (Fig. 8).

Para finalizar, tras los comentarios que anteceden y las comparaciones de la pintura aquí estudiada, con conocidas y seguras obras de Lucas Crananch se impone destacar la importancia que ésta adquiere para España, en razón no sólo de su firma y fecha de indudable autenticidad sino por no conocerse, que sepamos, otro ejemplar en el que figure, al dorso, la identificación del personaje retratado lo que la convierte en una, podríamos titular de, auténtica joyita por sus pequeñas dimensiones, para nuestro patrimonio artístico y en razón también, como apuntamos al inicio del trabajo, de la escasez de pintura alemana del siglo XVI que existe, desafortunadamente, en nuestro país (Figs. 2 y 3 ).

FRANS FLORIS DE VRIENDT (Amberes 1519-1520-Amberes, 1570) Los Cuatro Evangelistas. (102 x $172 \mathrm{~cm}$.). Ca. 1565-1566.

Pintura al óleo sobre tabla (Madrid. Colección particular) (Fig. 10).

Frans Floris procede de una familia de artistas; su padre Cornelis fue escultor-tallista de piedra pero su primera formación y sus trabajos de juventud no son bien conocidos, cuando el historiador de los pintores flamencos, Van Mander (1604) relata que ayudaba a su padre. Parece probable que su hermano mayor, Cornelis II, conocedor de la inclinación de Frans por la pintura, debió de convencerle para, que poco antes o justo en el momento de obtener su maestría en Amberes, 1540-1541, se trasladase a Lieja para aprender junto al pintor, de esta escuela, Lambert Lombard (Lieja 1505-Lieja 1566). Su formación artística la completó con una larga estancia en Roma entre 1541-1542 y 1545. Allí copió esculturas y relieves antiguos pero, también, obras de artistas italianos como el techo de la Capilla Sixtina y Juicio Final, de Miguel Ángel, las escenas de las Loggias y aún las decoraciones de la fachada de Polidoro de Caravaggio. Durante su estancia italiana trabajó, además, en otras ciudades entre ellas, Mantua donde copio los frescos de Julio Romano y Génova en donde consta pintó un tríptico, en 1543, para la tumba de la familia Del Berni en la iglesia de Santa Margarita, actualmente conservado en una colección particular de Roma ${ }^{5}$.

Es probable que estuviese de vuelta, en Arnberes, $c a$. 1545 y se sabe, con certeza, que en octubre de 1547 montó, en esta ciudad, un gran taller a la manera italiana de los de Rafael o Julio Romano, por el que pasaron buen número de discípulos y ayudantes. En el aspecto artístico también se inclinó por el modelo italiano con preferencia por el estilo de la escuela manierista que había conocido en Italia tomando como referentes más próximos, a Lucca Salviati y Pierino del Vaga.

Frans Floris supone, para la pintura flamenca de la segunda mitad del siglo XVI, una interesante aportación y a él se debe la introducción, en Amberes, de temas alegóricos que reproducen iconografias de la antiguedad lo que suscitó la transmisión de su influencia sobre los más conocidos pintores de la generación siguiente: Frans Pourbus el Viejo, los hermanos miembros de la familia Francken (Frans, Jerome o Hyeronimus, del que hablaremos y Ambroise) así como Crispín Van der Broeck.

Se conservan numerosas obras de Frans Floris, desafortunadamente otras muchas se perdieron con motivo de las revueltas religiosas del siglo XVI aunque bastantes de sus composiciones nos son conocidas gracias a su difusión a través de diversos y bien dotados grabadores de su tiempo.

\footnotetext{
${ }^{5}$ N. Dacos: Fiamminghi a Roma. 1508-1608. Bruselas, 1995, p. 189.
} 

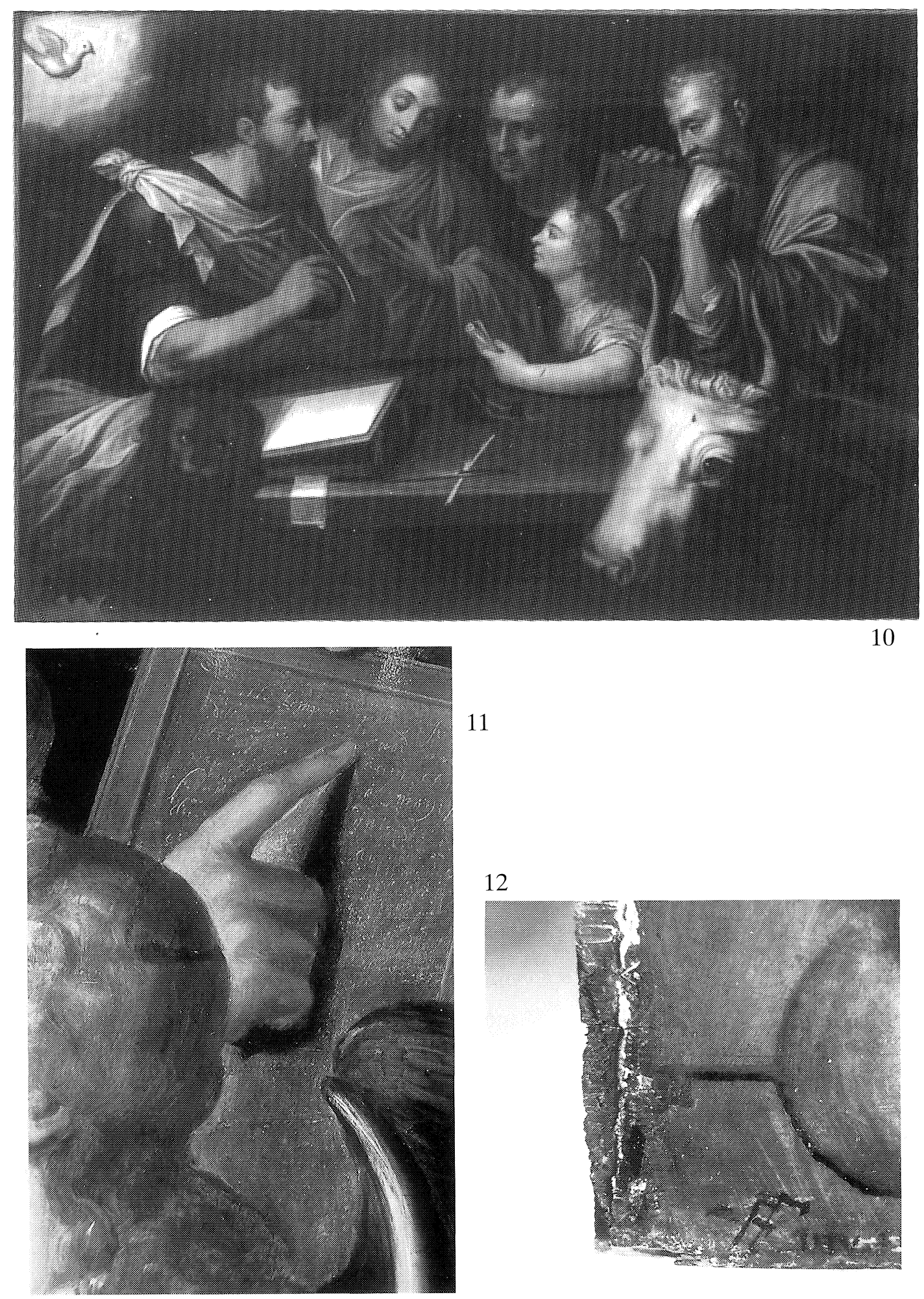

\section{1}

12

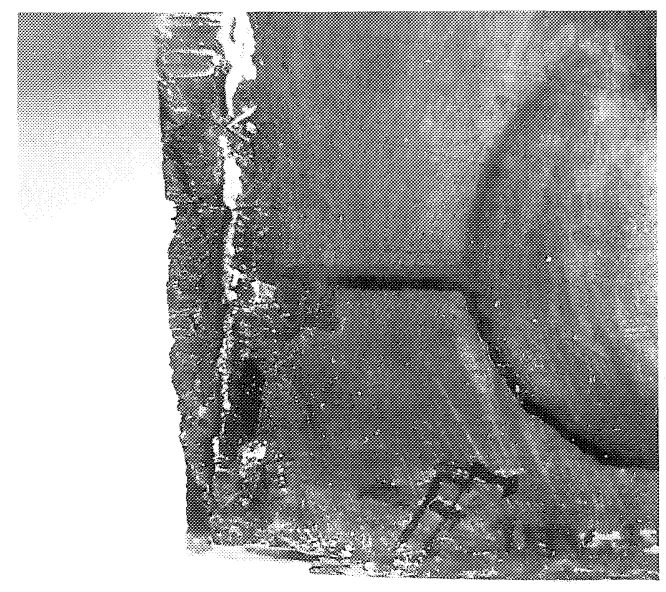

Figura 10. Frans Florís, Los cuatro Evangelistas. Madrid. Colección particular.

Figuras 11 y 12. Detalle índice San Lucas y cuerno del toro. Monograma del pintor. 


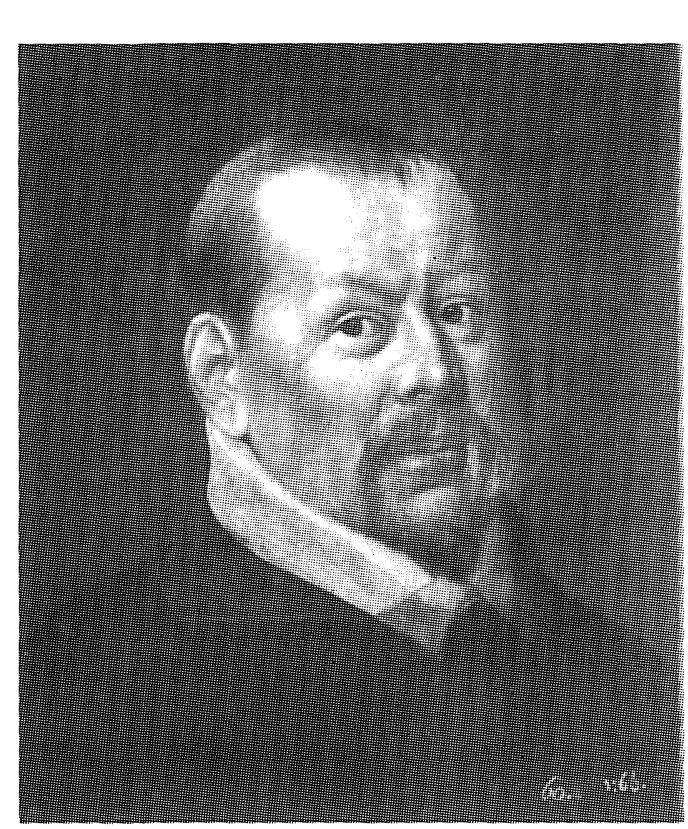

13
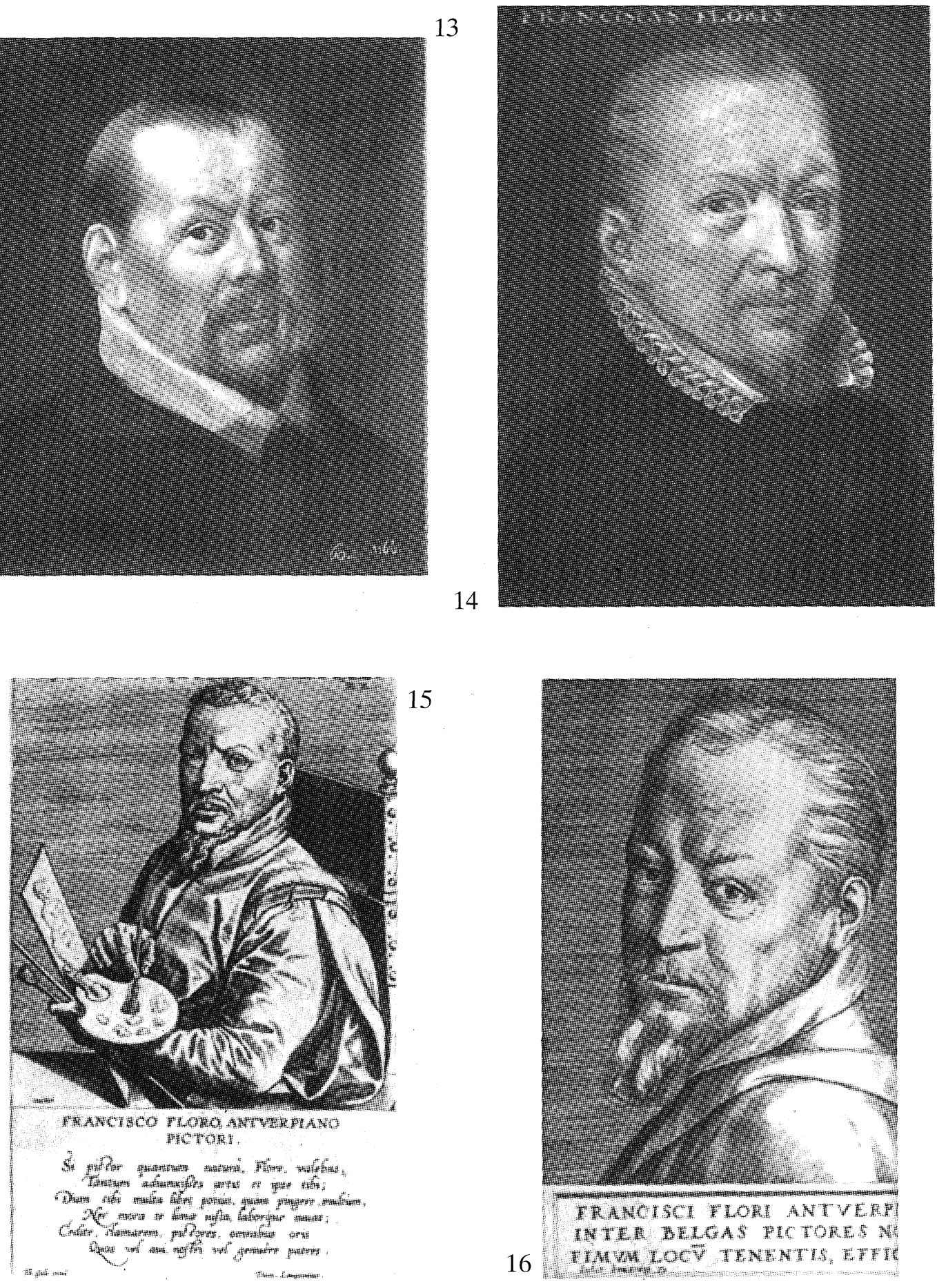

15

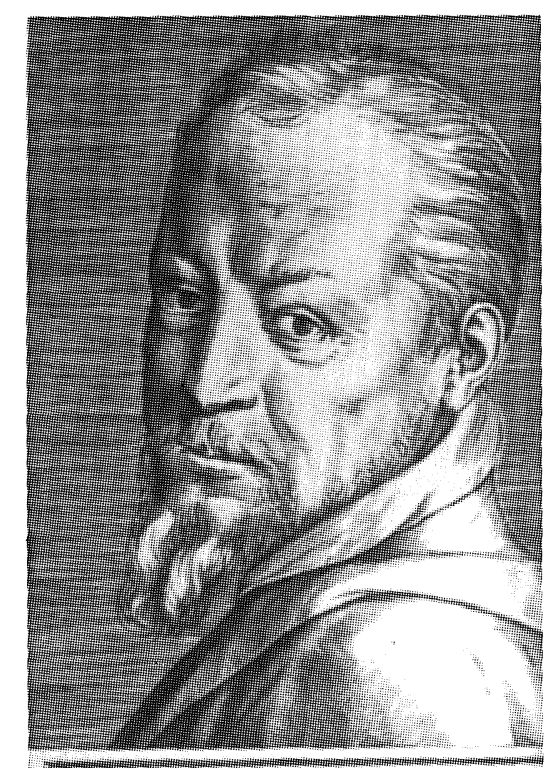

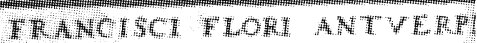

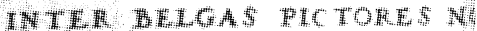

Figura 13. Copia de Frans Florís, Autoretrato. Viena. Kunsthistorisches Museum.

Figura 14. Copia de Frans Florís, Retrato del pintor.

Figura 15. J. Wierix, Retrato de Frans Florís.

Figura 16. G. Bonasone, Retrato de Frans Florís. 
Para analizar la espléndida tabla con los Cuatro Evangelistas de propiedad particular madrileña, que se estudia ahora por primera vez, hemos creído oportuno iniciar el trabajo con unas cuantas noticias de la biografía de su autor, Frans Floris, que pueden resultar muy indicativas para obtener una mejor comprensión del significado y calidades de la pintura así como de la probable fecha de su realización.

Es importante detenerse, un tanto, en la descripción de la escena porque, en nuestra opinión contiene aspectos y detalles que, sin duda, contribuyen a explicar algunos de los conceptos que su autor ha querido poner de manifiesto ante los ojos del futuro espectador. Ya la distribución de los personajes, que representan a los Evangelistas, puede resultar un tanto confusa si no se contempla, con detenida atención, algunos detalles, que a primera vista, pueden pasar desapercibidos. Por eso hay que tratar de situar la posición de cada personaje evangélico y la de cada uno de los cuatro símbolos iconográficos que tradicionalmente los representan.

La composición se resuelve con gusto por la simplificación del escenario que, para conseguir un ambiente de interior, se limita a colocar en el sentido horizontal, una mesa de gruesa madera en torno a la cual se distribuyen, a una misma altura, los cuatro protagonistas como clara alusión a una igual importancia jerárquica y todos dependientes del Espíritu Santo que, en su habitual forma de paloma, puede verse rodeado por luminosa abertura de Gloria, en el ángulo superior izquierdo, en fuerte contraste con el fondo oscuro del escenario y sin nada accesorio que sugiera impresión de espacio, algo de lo que Frans Floris va prescindiendo a medida que avanza su carrera artística. Por otra parte, hay que señalar el cariño de pintor, con oficio de la mejor tradición flamenca, con la que trata los utensilios o naturaleza muerta que apoyan sobre la mesa: atril con hoja aún en blanco, un papel que cuelga sobre el borde, un tintero negro con cordón rojo que sujeta el tapón y sobre todo, el cuchillo y la pluma de ave que aparecen, al borde central de la mesa, con sentido de inmediatez cotidiana, a punto de convertirse en un cálamo, para escribir, como el que sostiene, en su mano, el Evangelista Marcos que tiene delante el león que lo distingue. Siguiendo, de izquierda a derecha, el joven con vestiduras rojas que apoya contra su pecho la mano izquierda ha de ser San Juan aunque, el águila que le representa como Evangelista, apenas se aprecia y sólo es visible la cabeza con su largo pico que asoma tras la espalda de San Marcos. Hay que hacer un pequeño salto para localizar a San Mateo que está de perfil, en el lateral derecho, acodado sobre la mesa, la cabeza apoyada sobre la mano y la vista dirigida hacia el ángel, habitual compañía de Mateo, que roza con su ala oscura y por tanto poco visible, el brazo con el que sostiene la cabeza. Lo más interesante de esta pintura es, a nuestro juicio, la identificación de la figura que aparece tras el ángel de Mateo como el evangelista san Lucas, por razones que intentaremos convertir en evidencia.

En primer lugar, el personaje que suponemos representa a San Lucas, llama la atención por mirar de frente hacia el posible espectador y por el gesto de señalar, con su dedo índice, en una especie de simulada pizarra o tableta enmarcada. En segundo lugar, la importancia que concede al símbolo del toro que representa a este evangelista; por situación, tamaño, iluminación y tratamiento técnico como se aprecia, sobre todo, en la fuerza y realismo con que está realizado el ojo pero, también, resulta un tanto sorprendente la infrecuente longitud de sus cuernos de manera que, el derecho, alcanza a apuntar hacia el mismo lugar que el índice del personaje lo que parece indicar que, probablemente, el pintor Frans Floris, quiso atraer la atención del espectador a ese determinado espacio de la composición. En la pequeña pizarra, a la que aludimos, creemos ver restos de una inscripción en blanco cuyo texto no resulta fácilmente legible en el que, sin embargo, alguna palabra como magister, Franc y quizás 
Floris y nada más que pueda tener una segura transcripción, pudieran relacionarse con una posible firma del autor que, como veremos, lo hace con su conocido monograma, en el borde inferior de la tabla (Figs. 11 y 12).

De todos es conocido que algunos pintores, de todos los tiempos, se han sentido inclinados a representarse en la figura de San Lucas a quien se viene considerando como patrono de estos artistas y, Frans Floris pertenecía a la Cofradía o Gilda de San Lucas, de Amberes. Este patronazgo surge de la antigua leyenda que supone la existencia de un retrato, de la Virgen María, pintado por San Lucas. En cuanto a la sugerencia de que Frans Floris, autor de la pintura aquí estudiada, aparezca autorretratado en la figura de San Lucas, además de los detalles más arriba apuntados respecto a situación y actitud en la escena con la mirada de frente y la conexión con el toro que es su atributo, existe, a nuestro juicio, un notable parecido del personaje con retratos del pintor conocidos a través de copias o de grabados que nos muestran la imagen del artista y nada mejor que reproducirlos para llegar a percibir que su comparación, muestra el mismo tipo de ojos de mirada, un tanto dura, entrecejo fruncido y rostro en el que se adivina a un hombre de fuerte carácter y acusada personalidad (Figs. 13-16).

Se conserva una composición de grabador anónimo con el mismo tema de los Cuatro Evangelistas de nuestra pintura y resulta interesante porque aparece fechado en el centro, 1566 y firmado a la derecha: ffloris. in. ve. y aunque las variantes son muy notables, no cambia el concepto de la escena; fondo oscuro y liso, los personajes en torno a la mesa y el león y el toro delante de ella, aunque en el grabado todos aparecen de cuerpo entero. Lo reproducimos, sobre todo, para comprobar que, en éste último, el toro muestra una cornamenta normal y no con la excesiva longitud que, por los motivos apuntados, tienen los cuernos de la tabla madrileña (Fig. 17) ${ }^{6}$.

Los Museos Reales de Bruselas, conservan un tríptico de la Adoración de los Magos, de Frans Floris, que tiene pintados al interior, repartidos entre las dos puertas, a los Cuatro Evangelistas, con parecido sentido compositivo: distribución alrededor de la mesa, león y toro en el primer plano y este último con cuernos habituales como el del grabado anterior (Inv. $\mathbf{n}^{\mathbf{0}}$ 2786). Aludimos a esta obra porque aparece firmada y fechada en 1571, es decir ya al año siguiente de la muerte de Frans Floris pero se sabe que fue terminado por Jerome Francken que como queda dicho, al comienzo del estudio, fue uno de los discípulos de su taller ${ }^{7}$ (Fig. 18).

Una de las obras más famosas y conocidas de Frans Floris es el Juicio Final de los Museos Reales de Bellas Artes de Bruselas (Inv. n⿳0 92), con los Salvados y los Condenados en cada una de las puertas. Está firmado y fechado en 1566 y se advierte en los escorzos y la fuerza de los desnudos la inspiración del pintor en el Juicio, de Miguel Ángel, de Roma que sabemos había copiado durante su estancia en esta ciudad y otro Juicio Final, de su mano, fechado en 1565, se conserva en el Kunsthistorisches Museum de Viena ${ }^{8}$. En las dos obras Frans Floris repite, en la parte baja del centro del tríptico bruselense y en el Juicio de Viena, casi los mismos personajes y en las mismas posturas. Algunas de estas cabezas tienen grandes analogías con las de la obra que publicamos por lo que nos parece posible fecharla por estos años de $c a$. 1565-1566 (Figs. 19 y 20).

Como se dice, poco más arriba, la identificación de la pintura madrileña, con los Cuatro Evangelistas, como obra autógrafa de Frans Floris, se confirma con el monograma que figura

"C. Van de Velde: Frans Florís (1519/20-1570). Leven en Weken. Bruselas, 1975, Vol. I, nº 39, p. 404 y Vol. II, Fig. 192.

${ }^{7}$ Max J. Friédländer: Early Netherlandish Painting. Vol. XIII, Leyden/Bruselas, 1975, p. 88, nº 112, lám. 58.

Ibidem: ${ }^{\circ s} .116$ y $130 ;$ láms. 61 y 69. 

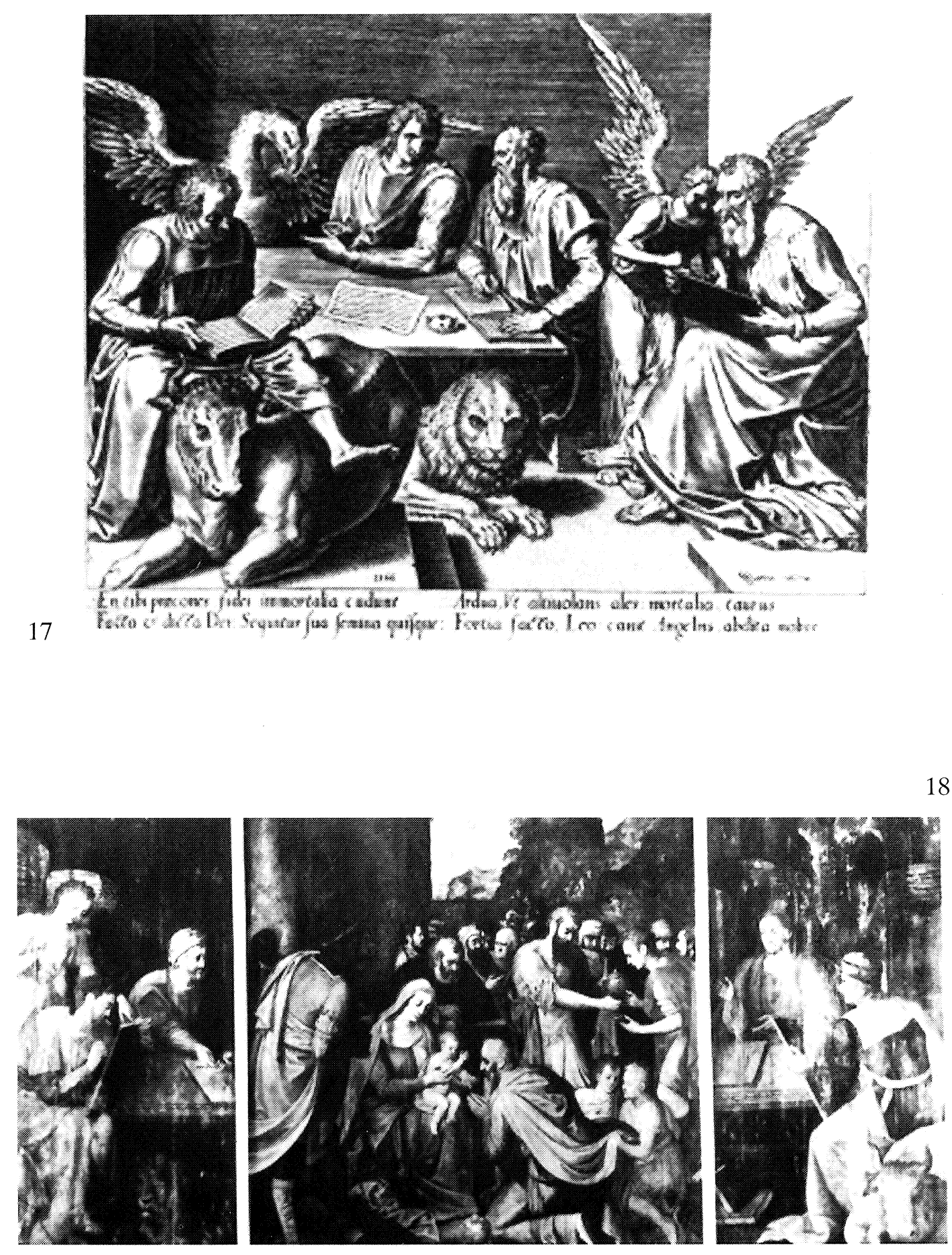

Figura 17. Grabador anónimo, Los cuatro Evangelistas.

Figura 18. Frans Florís: Tríplico Adoración de los Magos. Terminado en 1571 por Jerome Francken. Bruselas Musées Royales des Beaux-Arts. 


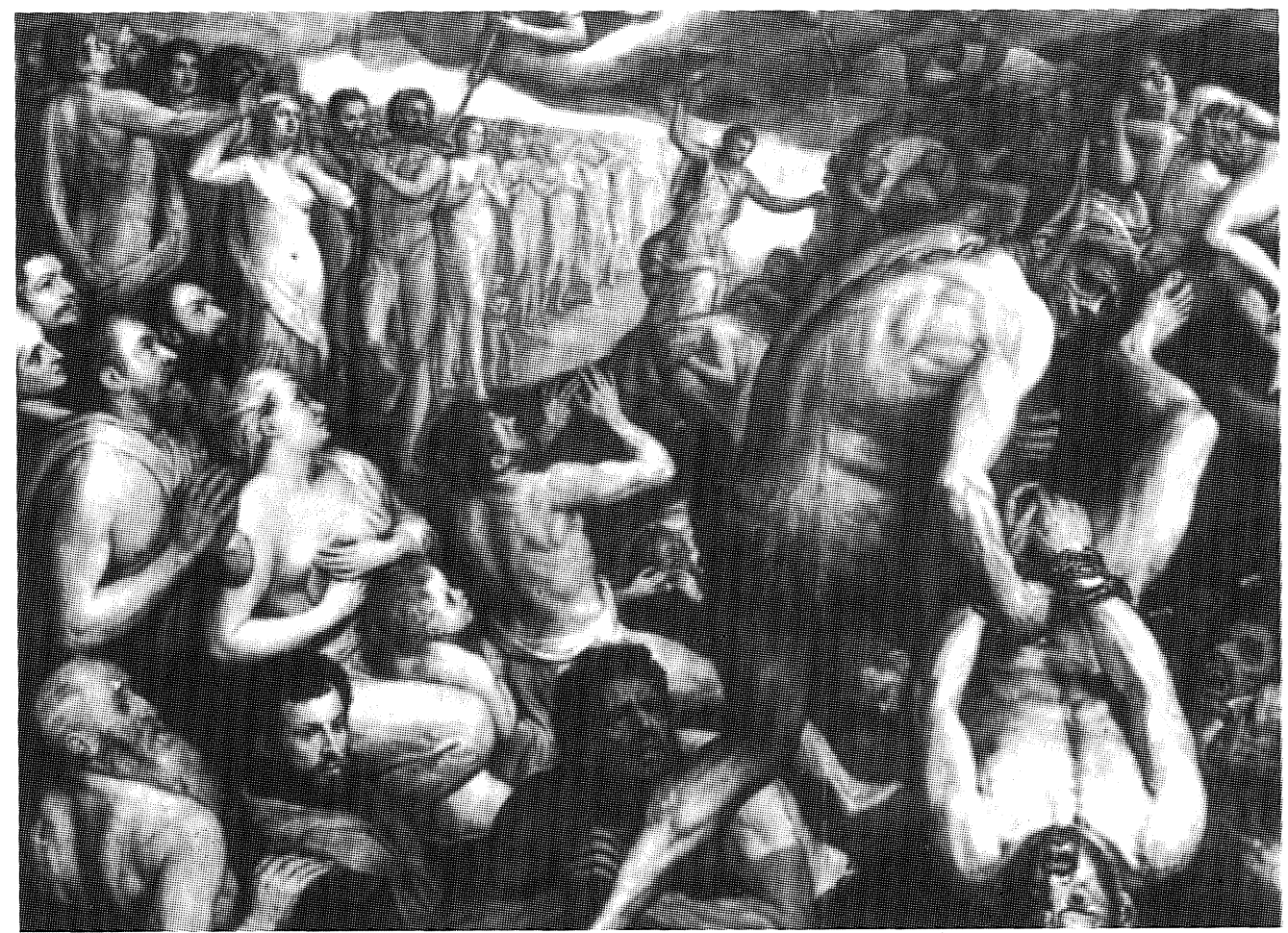

19

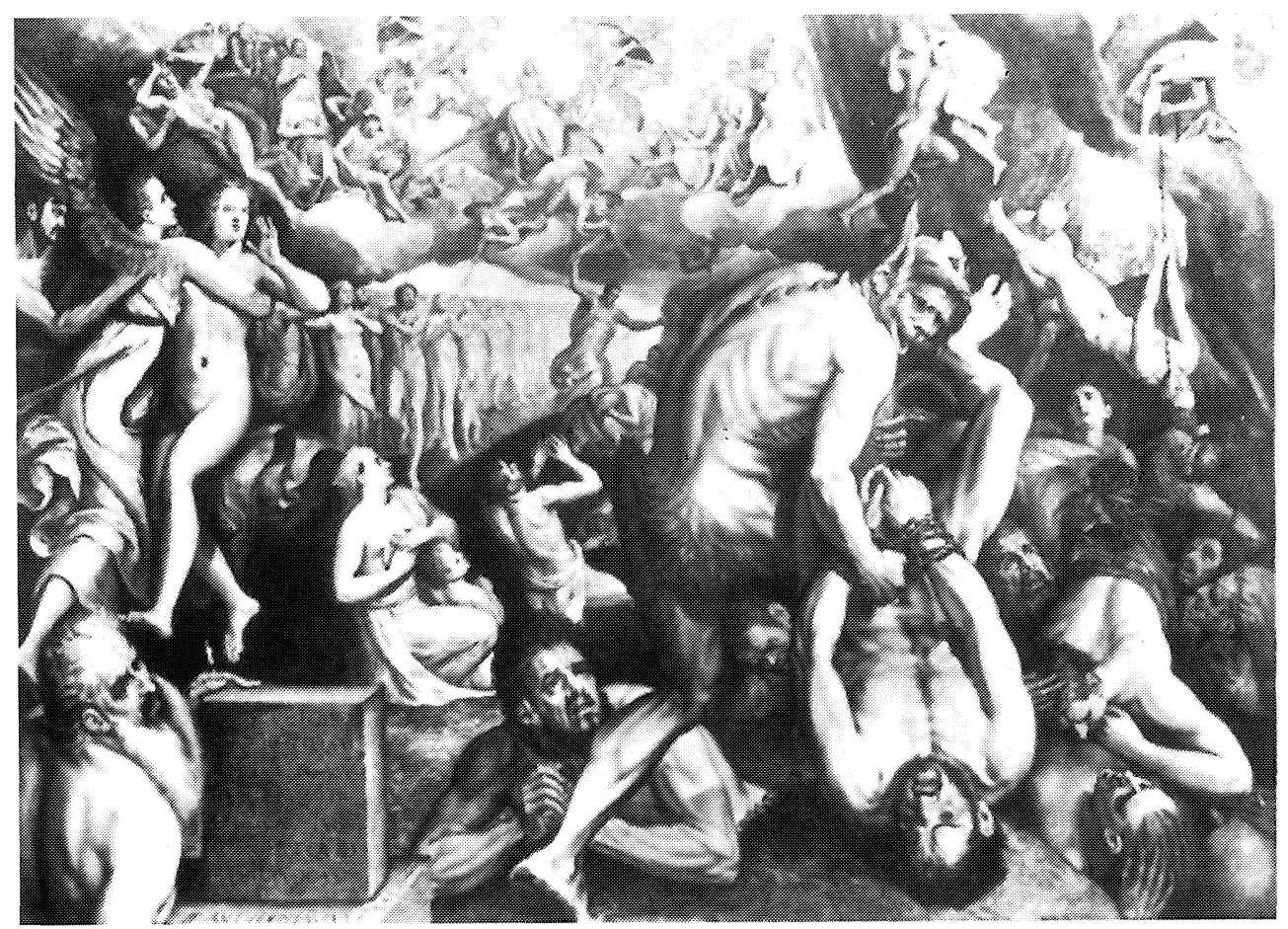

Figura 19 y 20. Frans Florís: Juicio Final. Detalle. Bruselas. Musées Royales des Beaux-Arts y Juicio Final. Amberes. Musée Royal des Beaux-Arts. Detalle. 
en esta tabla, que reproducimos, así como variantes del mismo y de su firma que utilizó en otras obras (Fig. 11). Sin relación directa con el tema es interesante recordar el único grabado, que se conserva, de su mano, la alegoría de la Victoria $(316$ x $435 \mathrm{~mm}$.). Firmado a la izquierda: frac s floris fecit. H. Cock excudebat A. 1552 y que se hizo para los Triunfos de la Entrada de Felipe II en Amberes en $1549^{9}$ (Fig. 21).

Dejamos para el final un detalle curioso, sin transcendencia en la pintura, pero que refuerza la intención del pintor de llamar la atención, cara al espectador, sobre el toro de San Lucas. Nos referimos a la pequeña mosca que aparece en la testuz del animal. D. Martens en su trabajo sobre $L$ 'ilusion du réel ${ }^{10}$ se ocupa, también, del «trampantojo» y dice al respecto: «Contrariamente a lo que se observa en el siglo XVII, el trampantojo es excepcional en el siglo XV. Sólo puede evocarse el caso de las moscas pintadas. El ejemplo conocido más antiguo, en el arte de los Países Bajos, se encuentra en el Retrato de un Cartujo de Petrus Christus, del Metrpolitan Museum, de Nueva York.» Este cuadro lleva un marco pintado en la misma tabla en el que la firma del pintor y la fecha (1446), ocupan la faz anterior mientras que, en el reborde interno, se aprecia una mosca: «El espectador se siente tentado de cazarla». Teniendo en cuenta que, de hecho, nadie espera encontrar un insecto en la atmósfera ideal de un cuadro del siglo XV, parece lógico que el espectador al contemplarlo, tenga tendencia a creerlo verdadero pues como dice Martens, «La mosca no puede ser más que un intruso» y por eso el pintor consigue el efecto de una presencia real.

Martens da también el ejemplo de otra tabla que representa a la Virgen con el Niño en un trono, atribuida al anónimo brujense conocido como de los «Retratos Baroncelli» (Berlín. Museo Bode) que también utiliza el detalle de la mosca, en este caso, posada sobre el brazo del trono y lo mismo que en el Retrato de un Cartujo de Christus, «su descubrimiento por el espectador da lugar a un efecto de ilusión (transgresión, imagen-realidad): la mosca parece hacer de la representación la primera realidad».

El Retrato del artista y su mujer, del maestro antuerpiano, conocido como «Maestro de Francfort» (aunque se propone el nombre de dos pintores como posible identificación), del Museo Real de Bellas Artes, de Amberes cuenta, también, con el motivo de la mosca que sorprende al espectador posada sobre el blanco cubrecabeza de la mujer. Está fechado en 1496 y lleva las armas de la Cofradía de San Lucas, de Amberes que integra, además, la divisa de la Cámara de los Retóricos de los «Violieren» que se había fusionado con la Gilda de San Lucas en 1480. Stephen Goddard dice en su trabajo sobre el «Maestro de Francfort» «que para reconstruir su obra, además de la iglesia dominicana de Francfort y de la familia Humbrach (de la que un miembro residía en Amberes), un mercader español y varias familias inglesas pueden razonablemente, identificarse como clientes del Maestro de Francfort» ${ }^{11}$ y 12 (Figs. 22 y 23).

En definitiva la tabla de Frans Florís con Los Cuatro Evangelistas, de propiedad privada, de Madrid, además de sus calidades técnicas y su belleza cromática nos comunica conceptos y detalles que contribuyen a perfilar la personalidad del pintor añadiendo a su catálogo de obras una pieza de excepcional importancia en la que, al hecho seguro de ser obra firmada, creemos se puede añadir el de poder conocer su fisonomía en los rasgos de San Lucas.

\footnotetext{
${ }^{9}$ C. Van de Velve: loc. cit. Vol. I, pp. 182-183 y 416. Vol. II, Fig. 230.

${ }^{10}$ D. Martens: «L'ilusion du réel» en Les Prikmitifs Flamands et leur temps. Bruselas, 1994, pp. 255-277.

${ }^{11}$ S. Goddard: «Les petis maîtres de la fin du XVe. siècle. Anvers: Le Maître de Francfort» en Les Primitifs Flamands et leur temps. Bruselas, 1994, pp. 568-571.

${ }^{12}$ Otra bibliografía sobre la «mosca». A. Pigler: «La mouche peinte: un talismán». Bulletin du Musée Hongrois des Beaux-Arts. XXIV, 1964, p. 56. D. Arasse: Le Detail. Pour une historie rapprochée de la peinture. Pau, 1992, pp. 77-85.
} 

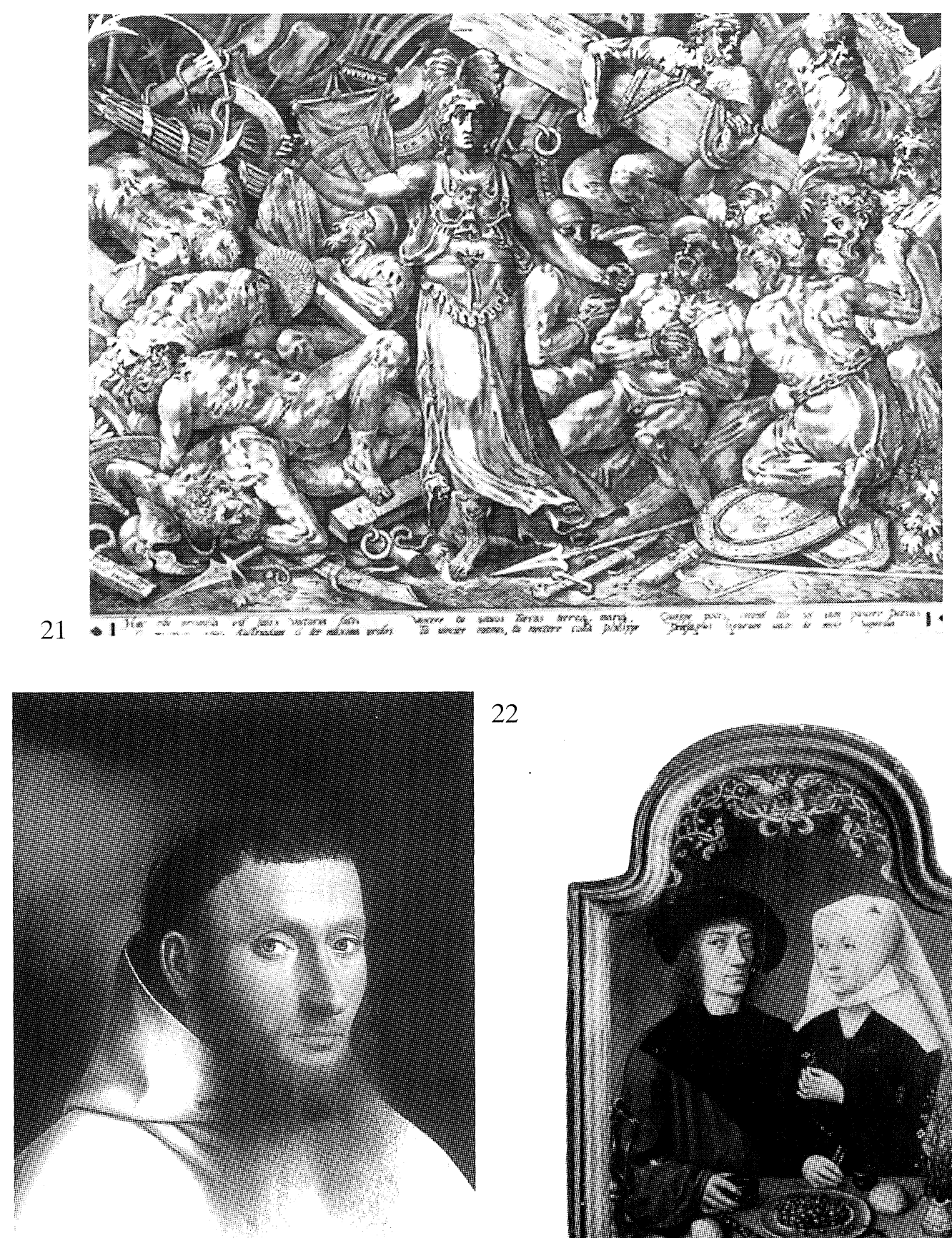

22
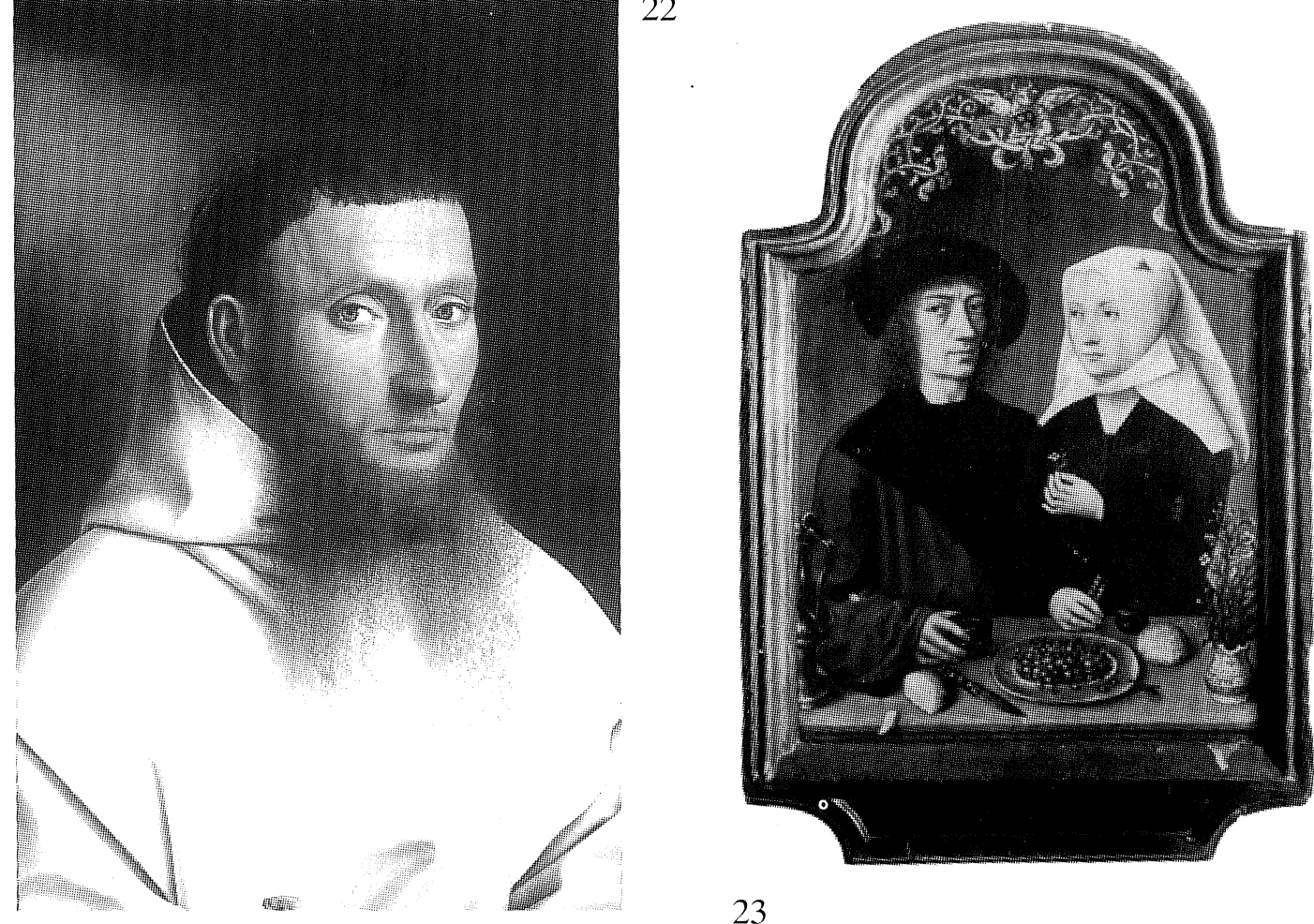

23

Figura 21. Frans Florís: Victoria. Grabado. Para Arco de Triunfo de los Genoveses, en Feliz Entrada de Felipe II en Amberes, en 1549.

Figuras 22 y 23. Petrus Christus: Retrato de un Cartujo. Nueva York. Metropolitan Museum. Maestro de Francfort: Retrato del artista y su mujer. Amberes. Musée Royal des Beaux-Arts. 